\title{
Rural school food service director perceptions on voluntary school meal reforms
}

\author{
Natoshia M. Askelson a* \\ University of Iowa \\ Disa Lubker Cornish b \\ University of Northern Iowa \\ Elizabeth Golembiewski c \\ University of Iowa
}

\begin{abstract}
Submitted January 6, 2015 / Revised March 12, March 24, May 13, and June 26, 2015 /
Accepted July 1, 2015 / Published online November 18, 2015

Citation: Askelson, N. M., Cornish, D. L., \& Golembiewski, E. (2015). Rural school food service

director perceptions on voluntary school meal reforms. Journal of Agriculture, Food Systems, and

Community Development, 6(1), 65-75. http://dx.doi.org/10.5304/jafscd.2015.061.007
\end{abstract}

Copyright (C) 2015 by New Leaf Associates, Inc.

\begin{abstract}
This mixed-method study examined rural U.S. food service directors' perceptions of and experiences with voluntary school meal programs, which have the potential to improve school nutrition but have not been widely adopted in rural areas of the United States. Little is known about how rural food service directors perceive these programs. Interview and survey instruments examined how

a* Corresponding author: Dr. Natoshia M. Askelson, Assistant Professor, Community \& Behavioral Health, University of Iowa; natoshia-askelson@uiowa.edu

b Dr. Disa Lubker Cornish, Assistant Professor, Health Promotion \& Education, University of Northern Iowa; disa.cornish@uni.edu

c Elizabeth Golembiewski, Research Assistant, Public Policy Center, University of Iowa; elizabethgolembiewski@,uiowa.edu
\end{abstract}

rural food service directors characterize barriers and facilitators to participation in voluntary school meal programs like farm-to-school and school garden programs. Rural school food service directors participated in a semistructured telephone interview $(n=67)$ and an online survey $(n=57)$. We defined rural school districts by the most rural locale codes (as categorized by the National Center for Education Statistics) in a midsized Midwestern state. Quantitative data were analyzed using descriptive statistics. We analyzed qualitative responses using thematic coding. The qualitative analysis revealed that directors had little experience with these programs and perceived these programs to be very challenging to implement. Issues common to rural school districts were a very small staff, lack of concrete knowledge about how these programs work, and lack of access to local producers and chefs. These findings underscore 
the need to consider the unique situation of rural schools when promoting voluntary school meals reform programs. We make recommendations about adopting and adapting these voluntary programs to better fit the reality of rural areas.

\section{Keywords}

nutrition, schools, school meals, health promotion, rural

\section{Introduction}

The U.S. Healthy, Hunger-free Kids Act of 2010 (HHFKA) was the first legislation in decades to dramatically change school meals. Some of these changes included increasing the portions of fruits, vegetables, and whole grains that are served, while limiting fat, calories, and sodium. Voluntary changes and programs such as farm-to-school and school gardens have been options for school food service programs to supplement healthy school meals and provide sustainable outlets for food procurements. None of these voluntary reforms and programs, however, has been widely adopted. Particularly little is known about how these programs are being implemented in rural school districts. This project examined the barriers and facilitators for rural school districts participating in these voluntary programs through interviews and online data collection with rural food service directors. Understanding issues related to adoption is important when school districts and local agencies are planning and implementing these programs.

\section{Background}

Obesity and overweight are a public health crisis in the United States, particularly among rural children (McGrath-Davis, Bennett, Befort, \& Nollen, 2011; Ogden, Carroll, Kit, \& Flegal, 2012; Singh, Kogan, \& van Dyck, 2008; Singh, Siahpush, \& Kogan, 2010). Rural children are less likely than their urban counterparts to eat healthy foods such as fruits, vegetables, and low-fat milk (Joens-Matre, Welk, Calabro, Russell, Nicklay, \& Hensley, 2008; Tovar et al., 2012). Additionally, adults living in rural areas are more likely to perceive their food environment as low quality and to report low access to grocery stores or fresh produce (Smith \& Morton, 2009; Damiano, Willard, \& Park, 2012).
Obesity and hunger coexist as serious public health problems among low-income adults and children (McMillan, 2014). As a result, school meals (including breakfast, lunch, and summer feeding programs) are an important source of nutrition for low-income and rural children experiencing food insecurity. However, rural food service directors often find themselves working to provide healthy meals on a shoestring budget, with limited financial resources. Approaches like collaborating with local growers, maintaining a school garden, and working with community members may provide solutions to challenges they face by increasing access to fresh food and student participation in meals.

There are many efforts nationally in support of voluntary school lunch reforms that aim to increase the nutritional quality of school meals; these include programs like school gardens, farm-toschool movements, and the Chefs Move to Schools initiative. Farm-to-school, school gardens, and chef-to-school programs, which compose the most widely implemented voluntary reform initiatives, are described in more detail below. There is some evidence that such efforts are slowly gaining acceptance among school districts; however, these programs are not yet widespread outside of urban areas (Turner \& Chaloupka, 2012). The U.S. Department of Agriculture (USDA) Farm to School Census shows that rural Midwest and Western states have lower participation rates than more urban states (USDA, n.d.). Previous research has not specifically examined rural school district participation in these programs and the barriers related to participation.

The aims of farm-to-school have been defined in the literature as to (1) serve locally produced foods in school cafeterias; (2) improve nutrition education in the classroom (including to educate students about the local food system); (3) develop and sustain school gardens; and (4) support local farmers and producers (Joshi, Azuma, \& Feenstra, 2008). Previous research suggests several benefits of farm-to-school efforts, including increased student knowledge and awareness of healthy foods, positive dietary and lifestyle changes among students and parents, and increased student meal participation (Colasanti, Matts, \& Hamm, 2012; 
Joshi, Azuma, \& Feenstra, 2008). Additionally, farm-to-school programs may function to support small and medium-sized farmers in rural communities, a currently shrinking demographic who may be seeking new distribution outlets. These farmers may enjoy direct economic gains through increased market diversification, and there may be social benefits from the knowledge that students in their community are benefiting from their locally grown produce (Izumi, Wright, \& Hamm, 2010).

However, research findings also suggest that significant barriers exist for schools attempting to implement farm-to-school programs. Barriers that have been identified in the literature include costs and availability of local foods, distribution logistics (such as delivery challenges), volume of food preparation needs, quality and reliability of local foods, food safety concerns, communication problems between schools and farmers, and problems with the seasonality of local produce (Colasanti, Matts, \& Hamm, 2012; Vo \& Holcomb, 2011). A recent ethnographic study highlighted the process of connecting a food service director with local farmers (Janssen, 2014). Throughout the process of connecting a food service director with local farmers, many barriers were apparent, including food service directors' lack of exposure to local farmers, and concerns about food safety. In addition, there may be perceived limitations to student tastes and an assumption that students will not "like" healthy foods (Poppendieck, 2010). We do not know specifically how rural school food service directors experience these barriers and challenges, which may have a greater impact in smaller communities with few local resources.

Voluntary programs include chef-to-school and school garden programs. Some evidence suggests that students consume more vegetables (Hanks, Just, \& Wansink, 2013) and whole grains (Cohen, Smit, Parker, Austin, Frazier, Economos, \& Rimm, 2012) when meals are prepared by chefs, but little research has been done about the implementation of such programs. School gardens have been shown to affect vegetable consumption, recognition of vegetables, attitudes towards vegetables, and preferences for and willingness to taste vegetables (Ratcliffe, Merrigan, Rogers, \& Goldberg, 2011). Additionally, school gardening may be associated with positive academic and social outcomes among participating students (Blair, 2009).

The purpose of our current research is to explore the experiences of rural school food service directors with voluntary school meal reform efforts in one rural, Midwestern state with low participation in farm-to-school and school gardens. Only 42 of the 348 school districts (12\%) in the state have some type of school garden in the district, and just $31 \%$ of the school districts report locally sourcing any of their food (Iowa Department of Agriculture, n.d.; USDA, n.d.). Specifically, we examined barriers and facilitators to participation in these programs.

\section{Methods}

We gleaned these findings from data collected as part of a larger study related to the experiences of rural school food service directors implementing the HHFKA changes. We used concurrent mixed methods: qualitative telephone-based interviews and an online questionnaire. Food service directors working in districts in the most rural locale codes (as categorized by the National Center for Education Statistics) were eligible for inclusion. We selected codes 42 (Rural Distant) and 43 (Rural Remote) to identify the most rural school districts. School districts in these categories include censusdefined rural territories that are 5 to 25 miles ( 8 to 40 kilometers) from an urbanized area, or 2.5 to 10 miles (4 to $16 \mathrm{~km}$ ) from an urban cluster, and school districts that are in a census-defined rural territory more than 25 miles $(40 \mathrm{~km})$ from an urbanized area and more than 10 miles $(16 \mathrm{~km})$ from an urban cluster. Informational letters were sent to the food service directors of these districts $(N=215)$, and follow-up contacts were made to invite study participation.

In the qualitative telephone interview, we asked respondents questions regarding knowledge, attitudes, and experiences with the HHFKA and voluntary reform programs. The interviews lasted approximately 20 minutes and were audio-recorded for later transcription. The quantitative instrument (online survey) included items about respondents' professional responsibilities, training experiences, day-to-day programming operations, and 
professional networks.

Qualitative analysis included close-ended coding of transcripts that led to the development of themes and codes based on interview guide content and initial reviews of the interview transcripts. Two trained researchers coded all 67 transcripts, first establishing intercoder reliability by coding two randomly selected transcripts and using a subjective assessment of coding results (Auerbach \& Silverstein, 2003). Finally, a third coder was brought in to discuss inconsistencies with the original two coders.

The study was approved by the University of Northern Iowa's Institutional Review Board.

\section{Results}

Sixty-seven food service directors completed the telephone interview and 57 directors completed the online survey. The respondents on average had worked in the food service industry for 9.2 years. A majority $(63 \%)$ of respondents said they had received some training or education after high school, most commonly in the form of statesponsored opportunities such as Extension service trainings. Very few respondents reported receiving any formal education after high school.

\section{Barriers to Participation}

Only 5 directors indicated experience with a voluntary program of any kind. Some expressed interest in or future plans for participating, but these plans included varying degrees of specificity. The most commonly reported barrier to participating was a lack of knowledge about available programming options and how to get started. Other answers centered on logistics, lack of time, lack of support, and lack of resources needed for full engagement in the programs.

\section{Lack of Knowledge}

Many respondents cited a lack of knowledge as a barrier to participation. Some simply did not know about any of the voluntary reform programs, while others were aware of the program possibilities but did not have time to seek out specific information to get a better understanding of how to implement such a program in their school or district. For example, one food service director described being at a loss about how to get a program off the ground:

I guess I would just need to talk to school board and administrators about... greenhouse here on the premises and they do plant plants for spring time sell... Used to be FFA but I'm not sure who sells it now. But they plant the little seeds and make plants and they sell them in the spring time...I'm not sure... I don't know how that would work. I'd have to talk to somebody about how that would work. [1047]

The new HHFKA requirements created uncertainty in some food service directors about which foods and procedures are allowable and what procurement regulations would apply through participation in a voluntary program. Obtaining foods from large or established vendors was preferable to procurement through local sources because the "red tape" had already been worked through:

I guess just maybe getting more information about like what I could or couldn't do... You don't want to do anything wrong and purchase anything that the government doesn't approve of. And so I think it is just easier for me to just get everything through my vendor then I don't have to worry about it. [1043]

\section{Logistical Issues}

Several respondents noted the lack of local growers in their area. Although rural school districts are often surrounded by corn or soybean farms, these crops are unfit for immediate consumption, and most respondents were unable to identify any local farmers growing crops that are viable for use in school meals.

Other logistical concerns included a general lack of knowledge regarding how to develop a system for regular delivery of local goods, including the lack of time available to pick up local produce from growers who were unable to deliver:

I really haven't been able to really figure out 
how to really get the ball rolling, like where you can get some of these fresh fruits and vegetables and stuff more year round to bring in. I mean I don't have time to just go and get them myself. [1013]

Safety concerns expressed were related to the logistics of how to handle potential hygienic or health issues. As one respondent stated,

My only thing is, I don't have the time to go and evaluate the food, and look it over and see what I think what will work and won't work. That's why I like the idea of it coming from my reputable vendor, I can order it, it comes, I don't have to worry about it. If there is a problem with it, I can go right back to him. [1005]

Respondents also raised concerns about the inability of small local farmers to accommodate the standards of institutional food service, such as limitations related to sanitation facilities, insurance, or the delivery of produce in a refrigerated truck:

The local farmers are not necessarily going to want to do what the government wants them to do. For instance putting a hand washing station in their field or you know they don't want to have to deal with that. [1011]

Additionally, some respondents had not been able to locate a chef in their area for the Chefs Move to Schools program. Respondents indicated that their school district was too far from any restaurants to attract a chef:

I checked into Chefs Move to Schools to ask someone to come in, some nutrition education and prep education or anything like that and there were no resources in [the state]. They told me there was not one resource in [the state] for Chefs Move to School [1038].

Other respondents believed that because their schools were small, their production volume would not be sufficient to attract any local farmers to work with them. Much of this sentiment seemed to originate from the difficulty that small, rural school districts have in attracting any vendors to provide food to them. As one respondent summed up: "We don't even have a local grocery store. I can't even get a person to deliver bread to my door" [1017].

\section{Lack of Support}

Respondents cited the lack of support from school boards, administrators, teachers, students, and parents as barriers. Respondents related this obstacle to both a lack of willingness from these parties to give time to support reform efforts and a lack of direct funding. For example, one food service director stated, "faculty [are] not interested and kids [are] not interested. I mean they would probably be interested if it was during school time but nobody wants to give up their private time to do anything like that" [1055]. Respondents noted a lack of time for students as a barrier to participation. As one food service director said, "Kids are too busy in a small district to get them to do it [school garden]" [1051].

\section{Lack of Time}

Respondents also reported it was not feasible to add any of these programs to their already busy days because their districts were small and had limited food service staff. Food service directors in rural districts face staffing shortages and lack the hours and/or volunteers needed to prep whole produce for the kitchen. Purchasing ready-to-eat (pre-prepared) foods from vendors lessens that perceived burden and also eliminates the issue of buying fresh produce in season during the year. As one respondent explained:

Also, I think just labor hours. From what I understand from just talking to one other food service director and maybe this is not true for everything, but they have a lot of volunteers come in and maybe wash the green beans or wash different vegetables and fruit. I think that would be hard to get people to come in and volunteer their time. That's one of the reasons...I guess another reason would 
be just, I'm so busy with the job now. [1025]

Directors also mentioned uncertainty regarding district policies that regulate whether volunteers are allowed to work in the kitchens at all: "No, I was told that no one is allowed in the kitchen except the cooks" [1061].

Some food service directors had attempted to engage in voluntary meal reform efforts, but made reference to negative experiences that would deter them from trying again in the future:

I tried the farm to school one and with the dry summer and stuff he had the last couple of years he had not a lot of stuff for me and so that kind of fizzled. They tried a garden before the fall started. That wasn't accessible at all. [1018]

I was under the impression he [the chef] was going to come in and show us how to do a few things but he just came in and went "what do you want me to do." You know and it's just like I was under the assumption he was going to bring some ideas with him. [1018]

\section{Experience Participating in Voluntary Programs} Although most respondents had not participated in a voluntary reform program, several food service directors had done so and experienced positive results. Items like tomatoes, cherry tomatoes, cucumbers, and peppers were popular among students in school gardens. Districts had successfully purchased apples and watermelons from local farmers and served them to students.

Several food service directors who reported positive experiences procuring local produce from community members, parents, and even their own gardens suggested creative, nontraditional sourcing solutions. For example, one district receives free produce from a local producer. Similarly, other respondents recounted how community members had called in to offer produce from their gardens. Another director advertised in the local newspaper that the school would accept food from gardens. Other nontraditional contributors of produce included a teacher who owns an apple orchard and one respondent's spouse who is an avid gardener.

Several food service directors reported having success with their own independent volunteer programs in the kitchens. Students volunteering in the kitchen provide additional staffing that decreases the burden on professional staff and allows for more planning time for directors. An additional benefit was that students gained a new perspective on the work happening in the school kitchens. One director explains how their student volunteer system works:

The kids have to meet certain requirements and they can come work in the kitchen. We also get them in here, and this sounds mean, but we have them trapped, where we can talk about, to them, what we have to do. A lot of them have seen the paperwork, they didn't understand that we did any paperwork and a lot of these kids didn't understand that we had guidelines. They just thought lunch ladies were mean and that's what they did. They just gave you food that...had to be healthy because that's what we choose in this kitchen to do so it's huge...opened a huge area for us with communication with these kids. [1062]

One respondent even reported that the student council had recognized that the kitchen was in need of help and developed a system to help with dishwashing and serving. At another school, high school students were working with elementary grades to introduce new fruits and vegetables.

\section{Benefits and Challenges Experienced}

Food service directors recognized a number of benefits to participating in voluntary programs. Some of the benefits were direct, such as children eating better food, learning about healthy eating, or simply having fun with food. Another noted benefit was that the fresher food secured by these programs tasted better. Some reported cost savings or supporting local businesses as benefits. Still others reported local community support as an advantage. 
Benefits to Students

Food service directors report that involving students in the kitchen has,

Just really changed the whole dynamic of our whole cafeteria, our whole kitchen. I have parents calling me with elementary kids that said I can't get my kids to tell me anything that happened at school today, just what happened at lunch because it's all positive. [1062]

Experience with school gardens benefits students, according to one director:

Well, it is fun to watch the kids plant their seeds and you know be out there with their little watering cans, you know water their plants and watch them grow.... And that's kind of exciting. I'm a gardener at heart so I enjoy things seeing kids doing this. [1006]

Food grown in the school garden or by local producers tasted better, according to some directors, and the students enjoyed taking part in these programs:

I think the kids get really excited. 'Cause when I have something fresh from a farmer, I make sure they know it and stuff. And the melons and stuff, they've just really, they've done really well with it. [1027]

\section{Cost and Time Savings}

For some directors, the local produce from farms or orchards was cheaper than items procured from their regular vendors. According to one director,

And I benefit because my cost is a fourth of what I would have to buy a watermelon from my distributor is eleven dollars and I get a watermelon for two dollars and fifty cents. So my budget definitely pans out on that. [1042]

Another director reported that because the local producer was so close, deliveries could be made in 5 minutes. Food service directors were excited about ways to include the community and parents in the process. According to one director, "Yeah so that's the best thing I guess, that it's kind of the community involved. And next year hopefully I could ask more parents to plant more tomatoes, cherry tomatoes, cucumbers" [1033].

\section{Challenges Experienced}

Food service directors who had tried a voluntary program commonly articulated barriers related to time, children being unwilling to eat the food, not having a reliable community partner, food volume, and weather. School gardens were problematic due to lack of proper upkeep. Because of limited time, the gardens were often not tended well, especially during the summer break, and volunteers were not interested in weeding. During the school year, children did not always have time to gather the produce, so food went to waste. One director found it was still difficult to get students to eat vegetables, even if they had been grown at the school. The volume of produce was a concern, both for schools that required larger volumes and that needed smaller volumes. Seasonality and weather issues were also challenges. The region had suffered from an extremely wet spring and a very dry summer and fall. These growing conditions negatively affected school gardens and local producers.

\section{Discussion}

Participation in voluntary school meal reform programs such as farm to school was not common among study respondents, which is true of other rural states (USDA, n.d.). Some of the barriers to participation reported by rural food service directors mirrored the challenges identified in the literature for urban schools, while some barriers appear to be unique to rural districts. These barriers include logistical issues related to space for a garden when the focus of farming is corn and soybeans, few local growers with small farms, no local restaurants for the Chefs Move to School program, and concerns about the small volume of food schools might need. Even respondents who had participated in voluntary programming reported some barriers and challenges along the way.

Among those respondents who had not taken 
part in farm to school programming, many simply did not know about the options available to them. These directors expressed a general lack of knowledge regarding a broad range of aspects related to voluntary programs. They were unsure about regulations, what programs were available, how to contact or communicate with potential vendors, the logistics of procurement, and other issues related to uncertainty about voluntary programs. Respondents also expressed little interest in seeking out programming possibilities or working to engage partners in such efforts. The lack of interest seemed to stem from the barriers to planning and implementation that appear to be very difficult to overcome. These issues and concerns related to adoption provide insights into ways program implementation might be facilitated or enhanced across other states with rural populations and low farm-to-school participation (USDA, n.d.).

In order to better support food service directors working in rural areas to implement successful voluntary programs, three intervention strategies should be pursued: (1) information about these programs needs to be communicated with rural food service directors; (2) tailored implementation strategies should be provided; and (2) professional and local community networks of people and agencies concerned about child nutrition need to be activated.

\section{Barriers}

The underlying barrier to participation in and implementation of voluntary reforms programs was often a lack of practical familiarity with these programs. This finding is echoed in other studies (Janssen, 2014) and may not be unique to rural areas. Food service directors may dismiss these programs at face value, believing that pursuing options like farm to school or school garden programs would add one more burden to their alreadyoverloaded schedules. Food service directors in rural areas need informational support from state departments of education and agriculture and from agencies responsible for Supplemental Nutrition Assistance Programs in order to understand how these programs can fit into food service operations at their schools and even make their jobs easier and more satisfying.
Rural food service directors articulated specific barriers related to rurality. For instance, in lower population areas there are fewer local growers because the population is not large enough to support these types of farmers. Fewer local growers mean less variety, less competition, and less security for rural food service directors. Many rural areas do not have restaurants to support a Chefs Move to School program. Additionally, rural food service directors struggle with vendors who are not willing to drive further to serve a school district with low volume. This concern appears to have carried over to rural food service directors' perceptions about local growers. They are worried that the small quantity they would order would not be of interest to local growers.

These findings support several possible intervention strategies that have been suggested in limited previous research (Rosenberg, 2012). In order to best support rural food service directors, they should be provided with resources, knowledge, and skills that are directly relevant to their daily work and tailored to local challenges and locally available tools. This support should come from the state agencies that are responsible for agriculture, education, public health, and food assistance, and those agencies responsible for the implementation of the HHFKA. In every state this configuration of agencies is unique.

Although they may not all be conscious of this fact, food service directors are part of local community networks that can be mobilized to improve the nutrition of rural children. This mobilization can come from the food service director, locally engaged parents or other community organizations working on issues of nutrition and hunger. The potential mutual benefits of engagement in these networks can support both the food service directors and the community partners (for example, increased business for small and midsize farmers). Many rural food service directors need assistance connecting with existing opportunities in their communities in sectors such as agriculture, restaurants, faith-based institutions, and others. Given the extensive barriers often faced by these directors, such as a deficit of time and financial resources, practical assistance in setting up voluntary programs could go a long way to 
contributing the logistical support these food service directors report that they lack. Significant community engagement is necessary to rally around schools to create opportunities for summer kitchen support.

In addition, given the distinct challenges faced by rural school food service programs, the use of creative adaptations to existing procurement models may be warranted in helping this population better implement school meal reforms. Thinking outside the box-beyond traditional food partners like restaurants and farms-food service directors could benefit from connecting with resources that already exist in rural areas such as long-term care facilities, food banks or food pantries, and faith-based institutions. Other potential partners in the venture to locally source food might be local community colleges (Feenstra, Allen, Hardesty, Ohmart, \& Perez, 2011) or local hospitals (Klein \& Michas, 2014), although these are not common in very rural communities. Likewise, these nontraditional partners could be drawn on to facilitate summer feeding programs to connect students to healthy foods. Many faithbased organizations and day-care centers operate on a year-round schedule and could provide sites for gardens.

In addition, it is important to begin discussions in rural communities with potential stakeholders in these activities. Qualitative and quantitative data collection should be conducted with small to midsized farmers, school administrators, community leaders, parent groups, faith-based organizations, day-care and other educational centers, farmers market boards, and other local groups that might be involved in community networks. Questions remain about the current state of those networks and ways in which they might be enhanced or expanded to the benefit of rural child nutrition.

A primary limitation of this study is the small sample size for the quantitative data portion. However, saturation was reached in the qualitative portion and descriptive analysis was possible with the sample size obtained. Larger sample sizes in future quantitative data collection will allow for between-group comparisons and additional depth of analysis.

\section{Conclusion}

This study improved understanding of the issues faced by rural school food service directors as they engage in considering, planning, and implementing voluntary school meal reform efforts such as farm to school, school gardens, and Chefs Move to Schools. Clearly, perceived and experienced barriers reduce willingness to become engaged and prevent rural schools from adopting new strategies. Providing tailored resources and activating professional and social networks may enhance the ability of rural school districts and communities to engage around the issue of child nutrition and voluntary reform efforts. Additional research is needed to understand how partners and stakeholders can become more involved and to understand how rural school districts might be uniquely supported in comparison to their more connected urban counterparts.

\section{References}

Auerbach, C. F., \& Silverstein, L. B. (2003). Qualitative data: An introduction to coding and analysis. New York: New York University Press.

Blair, D. (2009). The child in the garden: An evaluative review of the benefits of school gardening. Journal of Environmental Education, 40(2), 15-38. http://dx.doi.org/10.3200/JOEE.40.2.15-38

Cohen, J. F. W., Smit, L. A., Parker, E., Austin, S. B., Frazier, A. L., Economos, C. D., \& Rimm, E. B. (2012). Long-term impact of a chef on school lunch consumption: Findings from a 2-year pilot study in Boston middle schools. Journal of the Academy of Nutrition and Dietetics, 112(6), 927-933. http://dx.doi.org/10.1016/j.jand.2012.01.015

Colasanti, K. J. A., Matts, C., \& Hamm, M. W. (2012). Results from the 2009 Michigan farm to school survey: Participation grows from 2004. Journal of Nutrition Education and Behavior, 44(4), 343-349. http://dx.doi.org/10.1016/j.jneb.2011.12.003

Damiano, P. C., Willard, J. C., \& Park, K. (2012). The 2010 Iowa Child and Family Household Health Survey: Statewide report. Iowa City: Public Policy Center, The University of Iowa; Des Moines: Iowa Department of Public Health; and Iowa City: Child Health Specialty Clinics. Retrieved from http://ppc.uiowa.edu/health/study/iowa-childand-family-household-health-survey 
Feenstra, G., Allen, P., Hardesty, S., Ohmart, J., \& Perez, J. (2011). Using a supply chain analysis to assess the sustainability of farm-to-institution programs. Journal of Agriculture, Food Systems, and Community Development, 1(4), 69-85. http://dx.doi.org/10.5304/jafscd.2011.014.009

Hanks, A. S., Just, D. R., \& Wansink, B. (2013). Smarter lunchrooms can address new school lunchroom guidelines and childhood obesity. Journal of Pediatrics, 162(4), 867-869.

http://dx.doi.org/10.1016/j.jpeds.2012.12.031

Iowa Department of Agriculture. (n.d.). IDALS Farm to School participation. http://www.iowaagriculture. gov/AgDiversification/pdf/Farm2School/2014 springmap.pdf

Izumi, B. T., Wright, D. W., \& Hamm, M. W. (2010). Market diversification and social benefits: Motivations of farmers participating in farm to school programs. Journal of Rural Studies, 26(4), 374-382. http://dx.doi.org/10.1016/j.jrurstud.2010.02.002

Janssen, B. (2014). Bridging the gap between farmers and food service directors: The social challenges in farm to school purchasing. Journal of Agriculture, Food Systems, and Community Development, 5(1), 129-143. http://dx.doi.org/10.5304/jafscd.2014.051.012

Joens-Matre, R. R., Welk, G. J., Calabro, M. A., Russell, D. W., Nicklay, E., \& Hensley, L. D. (2008). Ruralurban differences in physical activity, physical fitness, and overweight prevalence of children. Journal of Rural Health, 24(1), 49-54. http://dx.doi.org/10.1111/j.1748$\underline{0361.2008 .00136 . x}$

Joshi, A., Azuma, A. M., \& Feenstra, G. (2008). Do farm-to-school programs make a difference? Findings and future research needs. Journal of Hunger and Environmental Nutrition, 3(2-3), 229-246. http://dx.doi.org/10.1080/19320240802244025

Klein, K., \& Michas, A. (2014). The Farm Fresh Healthcare Project: Analysis of a hybrid valuesbased supply chain. Journal of Agriculture, Food Systems, and Community Development, 5(1), 57-74. http://dx.doi.org/10.5304/jafscd.2014.051.003

McGrath-Davis, A., Bennett, K. J., Befort, C., \& Nollen, N. (2011). Obesity and related health behaviors among urban and rural children in the United States: Data from the national health and Nutrition
Examination Survey 2003-2004 and 2005-2006. Journal of Pediatric Psychology, 36(6), 669-676. http://dx.doi.org/10.1093/jpepsy/jsq117

McMillan, T. (2014, August). The new face of hunger. National Geographic. http://www.nationalgeographic. com/foodfeatures/hunger/

Ogden, C. L., Carroll, M. D., Kit, B. K., \& Flegal, K. M. (2012). Prevalence of obesity and trends in body mass index among US children and adolescents, 1999-2010. Journal of the American Medical Association, 307(5), 483-490.

http://dx.doi.org/10.1001/jama.2012.40

Poppendieck, J. (2010). Free for all: Fixing school food in America. Berkeley: University of California Press.

Ratcliffe, M. M., Merrigan, K. A., Rogers, B. L., \& Goldberg, J. P. (2011). The effects of school garden experiences on middle school-aged students' knowledge, attitudes, and behaviors associated with vegetable consumption. Health Promotion Practice, 12(1), 36-43. http://dx.doi.org/10.1177/1524839909349182

Rosenberg, N. (2012). Reducing obesity and fostering economic development through farm to school: Analysis and recommended actions. Retrieved from http://dash.harvard.edu/handle/1/11938742

Singh, G. K., Kogan, M. D., \& van Dyck, P. C. (2008). A multilevel analysis of state and regional disparities in childhood and adolescent obesity in the United States. Journal of Community Health, 33(2), 90-102. http://dx.doi.org/10.1007/s10900-007-9071-7

Singh, G. K., Siahpush, M., \& Kogan, M. D. (2010). Rising social inequalities in US childhood obesity, 2003-2007. Annals of Epidemiology, 20(1), 40-52. http://dx.doi.org/10.1016/j.annepidem.2009.09. $\underline{008}$

Smith, C., \& Morton, L. W. (2009). Rural food deserts: Low-income perspectives on food access in Minnesota and Iowa. Journal of Nutrition Education and Behavior, 41(3), 176-187. http://dx.doi.org/10.1016/i.jneb.2008.06.008

Tovar, A., Chui, K., Hyatt, R. R., Kuder, J., Kraak, V. I., Choumenkovitc, S. F.,...Economos, C. D. (2012). Healthy-lifestyle behaviors associated with overweight and obesity in US rural children. BMC Pediatrics, 12, 102. http://dx.doi.org/10.1186/14712431-12-102 
Turner, L., \& Chaloupka, F. J. (2012). Slow progress in changing the school food environment: Nationally representative results from public and private elementary schools. Journal of the Academy of Nutrition and Dietetics, 112(9), 1380-1389.

http://dx.doi.org/10.1016/j.jand.2012.04.017

United States Department of Agriculture [USDA]. (n.d.). The Farm to School census. Retrieved March 11,
2015, from http://www.fns.usda.gov/ farmtoschool/census\#/

Vo, A., \& Holcomb, R. B. (2011). Impacts of school district characteristics on farm-to-school program participation: The case for Oklahoma. Journal of Food Distribution Research, 42(3), 43-59.

http://purl.umn.edu/139431 